\title{
Quality of Care of Patients with Diabetes in Primary Health Services in Southeast Brazil
}

\author{
Christiane Chaves Augusto Leite Simão, Mônica Barros Costa, \\ Fernando Antônio Basile Colugnati, Elaine Amaral de Paula, \\ Chislene Pereira Vanelli, and Rogério Baumgratz de Paula
}

Postgraduate Program in Brazilian Health, School of Medicine, Federal University of Juiz de Fora, Avenida Eugênio do Nascimento, s/n, Bairro Dom Bosco, 36.038-330 Juiz de Fora, MG, Brazil

Correspondence should be addressed to Christiane Chaves Augusto Leite Simão; christiane.endocrino@hotmail.com

Received 16 December 2016; Revised 2 August 2017; Accepted 16 August 2017; Published 10 October 2017

Academic Editor: David Strogatz

Copyright (C) 2017 Christiane Chaves Augusto Leite Simão et al. This is an open access article distributed under the Creative Commons Attribution License, which permits unrestricted use, distribution, and reproduction in any medium, provided the original work is properly cited.

\begin{abstract}
Background. Diabetes management involves multiple aspects that go beyond drug therapy as a way of providing high quality care. The objective of this study was to describe quality of care indicators for individuals with diabetes in southeast Brazil and to explore associations among these indicators. Methods. In this cross-sectional, observational study, health care providers filled out a questionnaire addressing health care structure and processes at 14 primary health care units (PHCUs). Clinical and laboratory data of diabetic patients attending the PHCUs and from patients referred to a secondary health care (SHC) center were collected. Results. There was a shortage of professionals in $53.8 \%$ of the PHCUs besides a high proportion of problems regarding referrals to SHC. At the PHCU, glycated hemoglobin results were available only in half of the medical records. A low rate of adequate glycemic control was also observed. An association between structure and process indicators and the outcomes analyzed was not found. Conclusion. Major deficiencies were found in the structure and processes of the PHCUs, in addition to unsatisfactory diabetes care outcomes. However, no association between structure, process, and outcomes was found.
\end{abstract}

\section{Introduction}

The phenomenon of epidemiological transition, characterized by a change of focus from acute to chronic health conditions (CHC) as causes of morbidity and mortality, is a challenge to public health worldwide [1] as well as in Brazil, where the health needs have changed, requiring continuous and proactive attention focused on permanent care [2].

As a consequence, Mendes adapted the Chronic Care Model to the Brazilian Unified Health Care System [2]. In this proposal, health services are interconnected with the main purpose of delivering comprehensive care for specific health conditions [2], constituting the Health Care Networks (HCN). In this model of chronic care, the risk stratification of a specific population is a fundamental task of primary health care (PHC), which has a managerial role in the HCN [2].

It is noteworthy that essential elements of primary care include accessibility, longitudinality, comprehensiveness, and coordination [3]. In Brazil, PHC is provided through the Family Health Strategy (FHS), a successful program created in 1994. Since then, health indicators have improved in the country [4-7]. However, disparities in health care, particularly related to funding and organization, have been reported [6]. Restraints for an effective HCN coordination include lack of knowledge by PHC professionals regarding patient referral and difficulties in patients' access to specialized care [8].

As a $\mathrm{CHC}$, diabetes is becoming more prevalent, affecting approximately $7 \%$ of the adult Brazilian population [9] and most individuals with diabetes still demonstrate poor glycemic control $[10,11]$. It is worth noting that the morbidity and mortality associated with diabetes are related mainly to chronic complications of the disease that can be prevented by optimal metabolic control, along with self-care measures, periodic clinical follow-up, and prompt therapeutic intervention. Thus, a proper understanding of the clinical characteristics of the patients and the organizational aspects 
of the health system may help to improve decisions regarding the care of patients with diabetes and other CHCs [12].

The objective of this study was to describe the structure and process of PHC units (PHCUs) and the outcomes of patients with diabetes in a medium-sized municipality in southeast Brazil and to explore the association between these indicators.

\section{Methods}

In this observational cross-sectional study, PHC was evaluated in a medium-sized municipality in southeastern Brazil. Elements of structure, process, and results of the assistance were evaluated, according to the triad proposed by Donabedian [13].

Fourteen PHCUs were selected based on the electronic records of patients receiving shared attention at a SHC service. The units that had made the largest and the smallest number of referrals to the SHCU in each of the seven health regions of the city were included.

In order to analyze PHC structure and process an adapted questionnaire [14] and PHCU medical records were used. To evaluate the outcomes, data from charts in PHCU and from the SHC medical records were utilized. Data from the SHC unit were analyzed as a PHC outcome, as they were collected exclusively from each patient's first consultation at the specialized care unit.

Intending to analyze the physical and organizational characteristics of the PHCUs, a semistructured questionnaire, adapted from Pereira [14], was presented to the manager, one physician, and one community health agent (CHA) at each of the selected PHCUs, after obtaining informed consent.

The questionnaire included items evaluating the services provided to patients with $\mathrm{CHCs}$, which was divided, a posteriori, according to the categorization proposed by Donabedian [13] to evaluate structure and processes of the health care. Structure-related questions assessed material and human resources, as well as organizational structure. Processrelated questions analyzed strategies to provide medical care involving issues concerning the health team. The questions had dichotomous responses and were grouped in order to compose indicators summarizing the structure and process at each PHCU. Each response which indicated compliance with recommended guidelines [15-17] received one point, and the sum of these points was used to classify the structure and processes in each unit.

In each PHCU, the medical records of the patients diagnosed with diabetes, aged 18 years or more and of both sexes, who had had at least one medical appointment since 2010, were analyzed. The last two measurements of blood pressure (BP), fasting plasma glucose (FPG), glycated hemoglobin (HbAlc), and serum creatinine, along with estimated glomerular filtration rates (eGFR) calculated using the MDRD equation, were retrieved.

Data obtained from the PHCUs medical records were used as both indicators of process and outcomes, fulfilling the evaluation triad proposed by Donabedian [13]. As process indicators, the glycemic monitoring rate, defined as the proportion of individuals with diabetes with at least one
$\mathrm{HbAlc}$ result recorded in the medical charts during the year that preceded the collection of the data, was calculated. In addition, serum creatinine was used to calculate the renal monitoring rate. The results of BP, FPG, HbAlc, and eGFR were analyzed as outcomes of care.

In order to evaluate the outcomes, the computerized medical records of the patients in the SHC outpatient clinic were also analyzed. Data from the SHC unit were analyzed as a PHC outcome, as they were collected when the patients were initially admitted to the specialized care unit between August 2010 and December 2014. At this SHC unit, the parameters age, sex, educational level, income, tobacco use, alcohol use, medications in use, practice of physical exercise, weight, height, body mass index (BMI), BP, HbAlc, LDL cholesterol, and eGFR were collected from the patients' initial records. Those medical records of patients younger than 18 years of age and those in whom the absence of data in the medical records would compromise the research were excluded.

In the data analysis, the target levels of $\leq 130 \mathrm{mg} / \mathrm{dL}$ for FPG, $<7.0 \%$ for HbAlc, and $<140 \times 90 \mathrm{mmHg}$ were considered as indicative of adequate control in individuals with diabetes [15-17]. An eGFR $\leq 60 \mathrm{~mL} / \mathrm{min} / 1,73 \mathrm{~m}^{2}$ on a single occasion was regarded as suggestive of chronic kidney disease [15-17]. Respecting the frequency in which the tests were carried out in the PHCU, intervals shorter than 6 months for BP, FPG, and HbAlc were considered adequate [15-17]. With regard to the measurement of creatinine and calculation of eGFR, intervals shorter than 12 months were seen as appropriate [15-17].

2.1. Statistical Analysis. Categorical and quantitative variables were analyzed descriptively. The results are presented in percentages, mean and standard deviation, and median and interquartile interval. Associations between elements of the PHCUs' structure and process and the patients' clinical parameters upon admission to the SHC unit were explored with linear regression with random effects, using the data from the PHCUs as a conglomerate as we assumed that data from a single PHCU were not completely independent. The data were analyzed with the software SPSS 21.0 (SPSS Inc., Chicago, USA).

\section{Results}

3.1. Analysis of Questionnaires. Fourteen physicians, 13 managers, and $13 \mathrm{CHAs}$ were interviewed due to the fact that one of the selected PHCUs was not a FHS unit and lacked CHAs, and another had no manager when the data were collected. The average working years in PHC was $13 \pm 6.7$ among physicians, $14 \pm 7.6$ among managers, and $9 \pm 3.0$ among CHAs. The most important aspects of structure and processes of the PHCUs are shown in Table 1.

\subsection{Analysis of Medical Records}

3.2.1. Primary Health Care Units. A total of 844 medical records of registered patients with diabetes were analyzed, of whom 248 were excluded for having the most recent data 
TABLE 1: Elements of structure and process of the 14 evaluated PHCUs according to the questionnaire.

\begin{tabular}{lc}
\hline Structure & \\
Material resources & $38.5 \%$ \\
Availability of offices for consultation of patients with diabetes by a physician and a nurse on the same shift & $69.2 \%$ \\
Adequate number of blood glucose test strips & $30.8 \%$ \\
Sufficient number of diabetes medications to meet the demand of the unit & $69.2 \%$ \\
Availability of educational material on diabetes for the population & $46.2 \%$ \\
Human resources & CHA (53.8\%) \\
Completeness of the FHS team & $100 \%$ \\
Most frequently lacking professional & $72.7 \%$ \\
Physicians and nurses trained in FHS & $81.8 \%$ \\
Nursing assistants trained in FHS & $61.5 \%$ \\
CHAs trained in FHS & $92.3 \%$ \\
Organizational structure & $46.2 \%$ \\
Existence of scheduled nursing appointments for diabetes care & $69.2 \%$ \\
Existence of scheduled medical consultation for patients with diabetes & $69.2 \%$ \\
Active retrievability of diabetic patients who missed scheduled appointments & $69.2 \%$ \\
Problems related to coordination of care of patients with diabetes & $57.1 \%$ \\
$\quad$ Uncertainty about the unit where the patient should be referred to & $100 \%$ \\
$\quad$ Unawareness of the criteria for referral & $71.4 \%$ \\
Shortage of available appointments & $100 \%$ \\
\hline Processes & $21.4 \%$ \\
Recommendations about healthy eating and physical activity & $78.6 \%$ \\
Guidance regarding insulin application when indicated & $50 \%$ \\
Requests for FPG, HbAlc, creatinine, lipid profile, and urinalysis & $14.3 \%$ \\
Adequate return of test exams & $7.1 \%$ \\
BP measurement during all appointments & \\
Weight and height measurement during all appointments & \\
Screening for loss of protective plantar sensation in the feet & \\
Screening for retinopathy & \\
\hline
\end{tabular}

FHS: Family Health Strategy; CHA: community health agent; FPG: fasting plasma glucose; HbAlc: glycated hemoglobin.

TABLE 2: Clinical and laboratory data of patients with diabetes in the evaluated primary health care units.

\begin{tabular}{lcccc}
\hline Parameters & $\begin{array}{c}\text { Availability of } \\
\text { information, } n(\%)\end{array}$ & $\begin{array}{c}\text { Compliance with the } \\
\text { recommended interval, } n(\%)\end{array}$ & $\begin{array}{c}\text { Mean } \pm \text { SD } \\
\text { control, } n(\%)\end{array}$ & $\begin{array}{c}\text { Frequency of adequate } \\
\text { cont }\end{array}$ \\
\hline SPB (mmHg) & $596(100 \%)$ & $367(61.6 \%)$ & $134 \pm 20.3$ & $82 \pm 11.0$ \\
DBP (mmHg) & $596(100 \%)$ & $367(61.6 \%)$ & $154 \pm 69.0$ & $432(72.5 \%)$ \\
FPG (mg/dL) & $537(90.1 \%)$ & $138(23.1 \%)$ & $8 \pm 2.3$ & $274(46.0 \%)$ \\
HbAlc (\%) & $305(51.2 \%)$ & $86(14.4 \%)$ & $111(18.6 \%)$ \\
\hline
\end{tabular}

SBP: systolic blood pressure; DBP: diastolic blood pressure; FPG: fasting plasma glucose; HbAlc: glycated hemoglobin. Recommended intervals: blood pressure $\leq 6$ months; HbAlc $\leq 6$ months; FPG $\leq 6$ months.

recorded before 2010. These data were not collected from two of the PHCUs, one that had no record of patients with diabetes and another that declined our request to review the medical records.

Among the 596 medical records evaluated, the mean age of the patients was $64 \pm 12.8$ years and $67.3 \%$ were female. In addition, a total of $501(83.9 \%)$ patients had a diagnosis of hypertension in association with diabetes.

Regarding the information from physical examination and tests described in the medical records, a glycemic monitoring rate of $22.7 \%$ and a renal monitoring rate of $33.4 \%$ were observed. The mean eGFR was $75 \pm 32.7 \mathrm{~mL} / \mathrm{min} / 1,73 \mathrm{~m}^{2}$, and $25.5 \%$ of the patients had an eGFR below $60 \mathrm{~mL} / \mathrm{min}$ based on the last test result. Furthermore, BP was uncontrolled in $47.0 \%$ of the patients. The results of the remaining tests, along with their availability in the medical records and compliance with the recommended interval in the care of patients with diabetes, are shown in Table 2.

3.2.2. Secondary Health Care Unit. A total of 2,717 medical records were evaluated initially, but 23 were excluded because patients were under 18 years of age or chart data were 
TABLE 3: Characteristics of the patients with diabetes admitted to secondary health care outpatient clinics $(n=2,695)$ subdivided into those referred from the 14 PHCUs studied $(n=726)$ and those from other PHCUs $(n=1,969)$.

\begin{tabular}{|c|c|c|c|c|}
\hline & Total & PHCUs studied & Other PHCUs & $p$ value \\
\hline \multicolumn{5}{|l|}{ Sociodemographic data } \\
\hline Sex (\% women) & $61.9 \%$ & $62 \%$ & $61.9 \%$ & 0.156 \\
\hline Race (\% nonwhite) & $55.3 \%$ & $57.4 \%$ & $54.5 \%$ & 0.108 \\
\hline Education level & & & & 0.291 \\
\hline Illiterate & $6.1 \%$ & $4.7 \%$ & $6.7 \%$ & \\
\hline Incomplete elementary education & $61.6 \%$ & $64.2 \%$ & $60.6 \%$ & \\
\hline Complete elementary education & $15.8 \%$ & $15.7 \%$ & $15.8 \%$ & \\
\hline Complete secondary education & $13.8 \%$ & $12.7 \%$ & $14.3 \%$ & \\
\hline Complete higher education & $1.9 \%$ & $2.2 \%$ & $1.8 \%$ & \\
\hline \multicolumn{5}{|l|}{ Clinical data } \\
\hline Sedentary lifestyle & $21.7 \%$ & $22.3 \%$ & $21.5 \%$ & 0.113 \\
\hline Alcohol abuse & $13.7 \%$ & $12.5 \%$ & $14.1 \%$ & 0.562 \\
\hline Current smoking & $9.0 \%$ & $9.4 \%$ & $8.8 \%$ & 0.433 \\
\hline BMI (mean, kg/m²) & 31,00 & 31,04 & 30,91 & 0.670 \\
\hline Controlled BP & $43.9 \%$ & $42.8 \%$ & $45.5 \%$ & 0.202 \\
\hline Insulin use & $21 \%$ & $24.9 \%$ & $19.5 \%$ & 0.002 \\
\hline Metformin use & $69 \%$ & $68.2 \%$ & $69.2 \%$ & 0.622 \\
\hline Sulphonylurea use (\%) & $41 \%$ & $37.3 \%$ & $42.1 \%$ & 0.027 \\
\hline ACEI/ARB use (\%) & $65 \%$ & $68.7 \%$ & $63.9 \%$ & 0.020 \\
\hline Statin use (\%) & $55 \%$ & $58.1 \%$ & $53.4 \%$ & 0.300 \\
\hline Aspirin use (\%) & $44 \%$ & $47.4 \%$ & $42.3 \%$ & 0.018 \\
\hline \multicolumn{5}{|l|}{ Laboratory data } \\
\hline HbAlc (mean, \%) & 9.3 & 9.21 & 9.31 & 0.457 \\
\hline LDL (mean, mg/dL) & 116 & 116,71 & 116.17 & 0.848 \\
\hline eGFR (mean, $\mathrm{mL} / \mathrm{min}$ ) & 78 & 75.69 & 78.35 & 0.127 \\
\hline
\end{tabular}

BMI: body mass index; BP: blood pressure; ACEI: angiotensin-converting enzyme inhibitor; ARB: angiotensin receptor blocker; HbAlc: glycated hemoglobin; LDL: LDL cholesterol; eGFR: estimated glomerular filtration rate (MDRD).

incomprehensible, yielding 2,695 analyzed charts. The mean age of the patients was $60 \pm 13.1$ years and the mean annual household income was US\$7,533.36. An analysis of the results of tests which were considered to be important parameters of primary health care outcomes showed that $81.4 \%$ of the individuals admitted to the SHC unit were overweight or obese, $18.7 \%$ of them had HbAlc below 7\%, 36.5\% had LDL cholesterol below $100 \mathrm{mg} / \mathrm{dL}$, and $64.4 \%$ of the patients had an eGFR above $60 \mathrm{~mL} / \mathrm{min} / 1,73 \mathrm{~m}^{2}$. Table 3 shows the characteristics of these individuals, along with the subgroup of patients who were referred to by the 14 PHCUs whose structure and process were evaluated using the questionnaire.

A possible influence of characteristics related to the PHCUs' structure and processes on health care outcomes, inferred by the characteristics of the patients in their initial appointment at the SHC unit, are presented in Table 4. As shown in this table, no significant association was observed.

\section{Discussion}

Even though PHC is extremely important within the context of the HCNs, a high frequency of deficiencies in structure and, mainly, in processes in the PHCUs evaluated in this study were observed. Also, a high proportion of patients with diabetes did not reach the recommended targets for most health care outcomes.

The success of HCNs as a strategy to improve health care depends on the effectiveness of the PHC in terms of resolution, accountability, and coordination [15]. These attributes were hindered in our sample by the shortage of material resources in the PHCUs' structure. As for human resources, a shortage of CHAs in more than half of the units evaluated was observed, a finding similar to a Brazilian Midwest study that found a lack of CHA in 59.5\% of the teams evaluated [18]. It is worth noting that effective work by the CHAs is regarded as one of the most important components in FHS as it represents a link between the PHC and the community [6].

The high frequency of barriers in referring patients to SHC, reported in $70 \%$ of the PHCUs, must be emphasized, especially with respect to the site and criteria for the referral. Several studies have demonstrated this gap in coordination of care in the Brazilian Unified Health Care System $[19,20]$. Training in health care protocols and referral process has 
TABLE 4: Associations between structure and processes at primary health care and outcomes at secondary health care.

\begin{tabular}{|c|c|c|c|}
\hline Clinical parameters & Parameters used to evaluate the quality of health care & $\beta$ & $95 \% \mathrm{CI}$ \\
\hline \multirow{4}{*}{ HbAlc } & Structure points & 0.005 & $(-0.058 ; 0.068)$ \\
\hline & Process points & 0.236 & $(-0.063 ; 0.535)$ \\
\hline & Proportion with $\mathrm{HbAlc}$ results in the previous year & 0.399 & $(-2.740 ; 3.538)$ \\
\hline & Proportion with creatinine results in the previous year & 0.324 & $(-2.553 ; 3.201)$ \\
\hline \multirow{4}{*}{ LDL cholesterol } & Structure points & -1.903 & $(-3.269 ;-0.537)$ \\
\hline & Process points & 7.656 & $(0.492 ; 14.821)$ \\
\hline & Proportion with $\mathrm{HbAlc}$ results in the previous year & -68.814 & $(-141.718 ; 4.090)$ \\
\hline & Proportion with creatinine results in the previous year & 49.507 & $(-18.277 ; 117.291)$ \\
\hline \multirow{4}{*}{ eGFR } & Structure points & 0.678 & $(-0.479 ; 1.835)$ \\
\hline & Process points & -2.212 & $(-7.321 ; 2.896)$ \\
\hline & Proportion with $\mathrm{HbAlc}$ results in the previous year & 48.127 & $(-7.223 ; 103.477)$ \\
\hline & Proportion with creatinine results in the previous year & -62.586 & $(-114.121 ;-11.051)$ \\
\hline \multirow{4}{*}{ SBP } & Structure points & 0.021 & $(-0.815 ; 0.857)$ \\
\hline & Process points & 0.343 & $(-3.557 ; 4.244)$ \\
\hline & Proportion with $\mathrm{HbAlc}$ results in the previous year & -21.008 & $(-61.717 ; 19.701)$ \\
\hline & Proportion with creatinine results in the previous year & 10.109 & $(-27.227 ; 47.446)$ \\
\hline \multirow{4}{*}{ BMI } & Structure points & 0.100 & $(-0.079 ; 0.279)$ \\
\hline & Process points & -0.217 & $(-1.025 ; 0.591)$ \\
\hline & Proportion with $\mathrm{HbAlc}$ results in the previous year & -1.851 & $(-10.453 ; 6.751)$ \\
\hline & Proportion with creatinine results in the previous year & -1.450 & $(-9.432 ; 6.532)$ \\
\hline
\end{tabular}

$\beta$ : beta coefficient; CI: confidence interval; HbAlc: glycated hemoglobin; LDL: LDL cholesterol; eGFR: estimated glomerular filtration rate (MDRD); SBP: systolic blood pressure; BMI: body mass index.

been suggested as an effective strategy to improve quality indicators [21] and could be a solution for these shortcomings.

When the medical records at the PHCUs were analyzed, important process-related problems were also observed. Only $51.2 \%$ of the records of individuals with diabetes had results of HbAlc tests. Regarding the interval between these tests, the period of 6 months recommended by most guidelines for patients well controlled and with a stable disease $[15,16]$ was observed in only $14.4 \%$ of the patients. The glycemic monitoring rate of $22.7 \%$ in the PHCUs in our study was also below that described in the literature, which ranges from $30 \%$ to above $94 \%$ in developed countries [22-24].

Regarding chronic complications of diabetes, the renal monitoring rate was inadequate when compared with rates of 57.1-97.7\% reported by Stone et al. in eight European countries evaluated [23]. Low frequency of ophthalmoscopy and of screening for loss of protective plantar sensation was described by the physicians in this study. These rates are lower than those reported previously in Brazil [25]. Actually, the frequency of both examinations varies worldwide $[22,23,26]$.

In terms of health care results, a low percentage of patients with adequate metabolic control were found. Levels of HbAlc below 7\% were observed in less than a fifth of the medical records. These rates are lower than those described in Brazilian studies $[10,11]$ and contrast even more with data from Europe and the United States, which range from 35.7\% to $70.5 \%[23,24]$. However, the findings of our study should be interpreted with caution given the low frequency of $\mathrm{HbAlc}$ results available in the medical records analyzed.
With regard to comorbidities associated with diabetes, the outcomes were also unsatisfactory. Adequate BP control was observed in $53 \%$ of the patients with diabetes in the PHCUs, a rate higher than that described in the general Brazilian population (19.6\%) [17], but lower than the data observed in an endocrinology outpatient clinic in south Brazil [27]. In other countries, most of studies found a higher percentage of adequate $\mathrm{BP}$ control in patients with diabetes $[24,26]$. Excessive body weight was a frequent finding in the studied sample, and similar data was described in several studies related to the quality of diabetes care [11, 23, 27]. The proportion of patients with LDL cholesterol levels below $100 \mathrm{mg} / \mathrm{dL}$ in the present study was lower than that reported in patients assisted in another Brazilian SHC service [27]. Actually, the rates observed in different populations are very heterogeneous [22, 23].

With respect to the treatment of diabetes, the population admitted to the SHC unit in this study showed a lower frequency of insulin use when compared to countries such as Germany, Italy, Sweden, United Kingdom [23] and to Brazilian studies [10,11]. However, the population analyzed in the present study included patients for whom insulin should have been prescribed and could not be implemented in a PHCU. In contrast, the frequency of use of aspirin and statin was greater than that described in other patients with diabetes [26].

No statistical or clinical significance was found when possible associations among parameters of structure and process with clinical outcomes were evaluated. Similar data have been described by Wesselink et al. in the Netherlands 
[28] and by Sidorenkov et al., in a systematic review, thus pointing out to the need for robust indicators of health care quality [29]. In addition, it is worth noting that the results are not direct measures of the initiatives of the health professionals and may be influenced by other factors, such as lifestyle and socioeconomic circumstances, over which the institutions and care providers have no control [30].

The questionnaire used to evaluate the PHCUs was an adapted version and could be pinpointed as a limitation in the present study. However, the evaluation of the quality of medical care has been challenging for decades [13], possibly due to the absence of a consolidated instrument for this purpose. On the other hand, it must be emphasized that this is a real-life study whose findings could contribute to health policy planning in primary care.

\section{Conclusion}

In the present study, major deficiencies were found in the structure and processes of the PHCUs, in addition to unsatisfactory diabetes care outcomes. However, no association between structure, processes, and outcomes was found. Additional studies are required to identify the most relevant indicators of structure and processes in order to improve the quality of care of individuals with diabetes.

\section{Ethical Approval}

The study was authorized by the Municipal Health Secretariat of Juiz de Fora and approved by the Ethics Committee for Research Involving Human Subjects at the University Hospital of the Federal University of Juiz de Fora.

\section{Consent}

All participants interviewed gave a written consent to participate in the study.

\section{Disclosure}

The views expressed in this manuscript are those of the authors and not necessarily those of the FAPEMIG.

\section{Conflicts of Interest}

The authors declare that there are no conflicts of interest regarding the publication of this paper.

\section{Acknowledgments}

The authors acknowledge the Fundação de Amparo à Pesquisa do Estado de Minas Gerais (FAPEMIG) for funding this research.

\section{References}

[1] D. Yach, C. Hawkes, C. L. Gould, and K. J. Hofman, "The global burden of chronic diseases: overcoming impediments to prevention and control," The Journal of the American Medical Association, vol. 291, no. 21, pp. 2616-2622, 2004.
[2] E. V. Mendes, "O cuidado das condições crônicas na atenção primária à saúde: o imperativo da consolidação da estratégia da saúde da família. Brasília," Organização Pan-Americana da Saúde, 2012, http://bvsms.saude.gov.br/bvs/publicacoes/cuidado_condicoes_atencao_primaria_saude.pdf.

[3] B. Starfield, "Is primary care essential?” The Lancet, vol. 344, no. 8930, pp. 1129-1133, 1994.

[4] R. Atun, S. Jaffar, S. Nishtar et al., "Improving responsiveness of health systems to non-communicable diseases," The Lancet, vol. 381, no. 9867, pp. 690-697, 2013.

[5] A. Klafke, B. B. Duncan, A. Stevens et al., "The decline in mortality due to acute complications of diabetes mellitus in Brazil, 1991-2010," BMC Public Health, vol. 15, no. 1, article no. $772,2015$.

[6] J. Macinko and M. J. Harris, "Brazil's family health strategy Delivering community-based primary care in a universal health system," New England Journal of Medicine, vol. 372, no. 23, pp. 2177-2181, 2015.

[7] D. Rasella, M. O. Harhay, M. L. Pamponet, R. Aquino, and M. L. Barreto, "Impact of primary health care on mortality from heart and cerebrovascular diseases in Brazil: A nationwide analysis of longitudinal data," BMJ (Online), vol. 349, Article ID g4014, 2014.

[8] L. B. B. Rodrigues, P. C. D. S. Silva, R. C. Peruhype et al., "Primary health care in the coordination of health care networks: An integrative review," Ciencia e Saude Coletiva, vol. 19, no. 2, pp. 343-352, 2014.

[9] The Brazilian Institute of Geography and Statistics, "National Survey of Health 2013," 2015, http://biblioteca.ibge.gov.br/visualizacao/livros/liv94074.pdf.

[10] A. B. V. Mendes, J. A. S. Fittipaldi, R. C. S. Neves, A. R. Chacra, and E. D. Moreira Jr., "Prevalence and correlates of inadequate glycaemic control: results from a nationwide survey in 6,671 adults with diabetes in Brazil," Acta Diabetologica, vol. 47, no. 2, pp. 137-145, 2010.

[11] L. V. Viana, C. B. Leitão, C. K. Kramer et al., "Poor glycaemic control in Brazilian patients with type 2 diabetes attending the public healthcare system: A cross-sectional study," BMJ Open, vol. 3, no. 9, Article ID e003336, 2013.

[12] A. Bello, B. Hemmelgarn, B. Manns, and M. Tonelli, "Use of administrative databases for health-care planning in CKD," Nephrology Dialysis Transplantation, vol. 27, no. 3, pp. iii12-iii18, 2012.

[13] A. Donabedian, "The quality of care. How can it be assessed?" Journal of the American Medical Association, vol. 260, no. 12, pp. 1743-1748, 1988.

[14] P. M. H. Pereira, Avaliação da atenção básica para o diabetes mellitus na Estratégia Saúde da Família [Master's dissertation in Public Health], Fundação Oswaldo Cruz, 2007.

[15] Ministério da Saúde, "Secretaria de Atenção à Saúde. Departamento de Atenção Básica. Estratégias para o cuidado da pessoa com doença crônica: diabetes mellitus," 2014, http:// bvsms.saude.gov.br/bvs/publicacoes/estrategias_cuidado_pessoa diabetes_mellitus_cab36.pdf.

[16] "Standards of Medical Care in Diabetes," in Diabetes Care, 1, pp. S1-S112, 2016.

[17] Sociedade Brasileira de Cardiologia, Sociedade Brasileira de Hipertensão, and Sociedade Brasileira de Nefrologia, "VI Diretrizes Brasileiras de Hipertensão," Arquivos Brasileiros de Cardiologia, vol. 95, 1, no. 1, pp. 1-51, 2010. 
[18] Macedo CLSV, Avaliação da Estratégia de Saúde da Família do município do Cabo de Santo Agostinho-PE quanto às dimensões de estrutura, processo e resultado, Fundação Oswaldo Cruz, 2013.

[19] P. F. Almeida, L. Giovanella, M. H. M. Mendonça, and S. Escorel, Challenges for healthcare coordination: strategies for integrating levels of care in large cities, vol. 26, Saúde Pública, 2010.

[20] I. R. S. Aleluia, M. G. Medina, P. F. Almeida, and A. L. Q. Vilasbôas, "Care coordination in primary health care: an evaluative study in a municipality in the Northeast of Brazil," vol. 22, no. 6, pp. 1845-1856, 2017.

[21] A. Frølich, J. Bellows, B. F. Nielsen, P. B. Brockhoff, and M. Hefford, "Effective population management practices in diabetes care - an observational study," BMC Health Services Research, vol. 10, p. 277, 2010.

[22] B. E. Landon, L. S. Hicks, A. J. O’Malley et al., "Improving the management of chronic disease at community health centers," New England Journal of Medicine, vol. 356, no. 9, pp. 921-934, 2007.

[23] M. A. Stone, G. Charpentier, K. Doggen et al., "Quality of care of people with type 2 diabetes in eight European Countries: Findings from the guideline adherence to enhance care (GUIDANCE) study," Diabetes Care, vol. 36, no. 9, pp. 2628-2638, 2013.

[24] M. J. E. Campmans-Kuijpers, C. A. Baan, L. C. Lemmens, M. L. H. Klomp, A. C. M. Romeijnders, and G. E. H. M. Rutten, "Association between quality management and performance indicators in Dutch diabetes care groups: A cross-sectional study," BMJ Open, vol. 5, no. 5, Article ID e007456, 2015.

[25] E. Tomasi, M. A. D. C. Cesar, R. G. Neves et al., "Diabetes care in Brazil program to improve primary care access and qualityPMAQ," Journal of Ambulatory Care Management, vol. 40, no. 2, pp. S12-S23, 2017.

[26] A. C. Tricco, N. M. Ivers, J. M. Grimshaw et al., "Effectiveness of quality improvement strategies on the management of diabetes: a systematic review and meta-analysis," The Lancet, vol. 379, no. 9833, pp. 2252-2261, 2012.

[27] D. R. Baptista, R. D. Thieme, W. C. T. Reis, R. Pontarolo, and C. J. Correr, "Proportion of Brazilian diabetes patients that achieve treatment goals: Implications for better quality of care," Diabetology and Metabolic Syndrome, vol. 7, no. 1, article no. 107, 2015.

[28] S. F. O. Wesselink, H. F. Lingsma, P. B. M. Robben, and J. P. Mackenbach, "Guideline adherence and health outcomes in diabetes mellitus type 2 patients: A cross-sectional study," BMC Health Services Research, vol. 15, no. 1, article no. 22, 2015.

[29] G. Sidorenkov, F. M. Haaijer-Ruskamp, D. De Zeeuw, H. Bilo, and P. Denig, "Relation between quality-of-care indicators for diabetes and patient outcomes: a systematic literature review," Medical Care Research and Review, vol. 68, no. 3, pp. 263-289, 2011.

[30] J. Mant, "Process versus outcome indicators in the assessment of quality of health care," International Journal for Quality in Health Care, vol. 13, no. 6, pp. 475-480, 2001. 


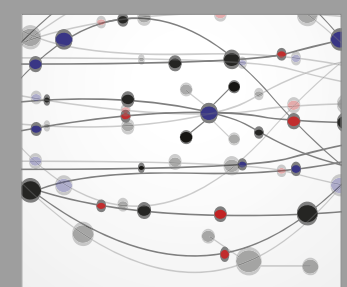

The Scientific World Journal
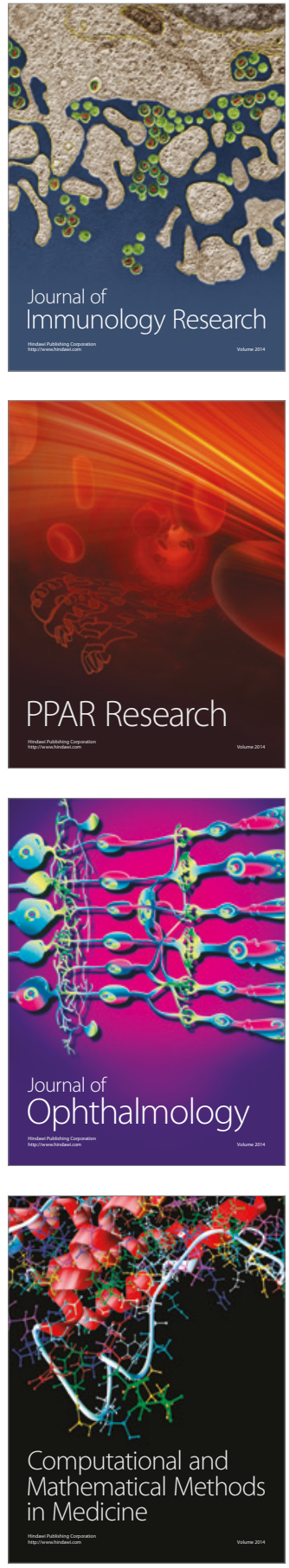

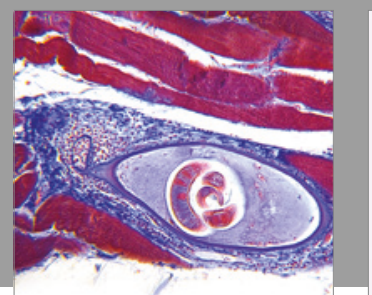

Gastroenterology Research and Practice
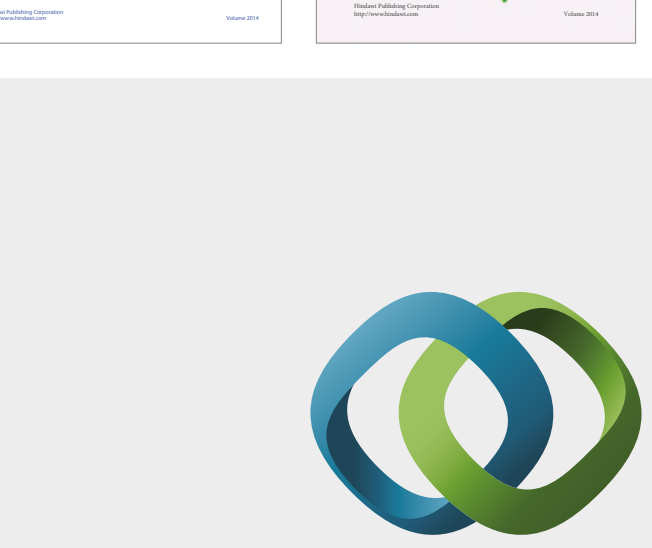

\section{Hindawi}

Submit your manuscripts at

https://www.hindawi.com
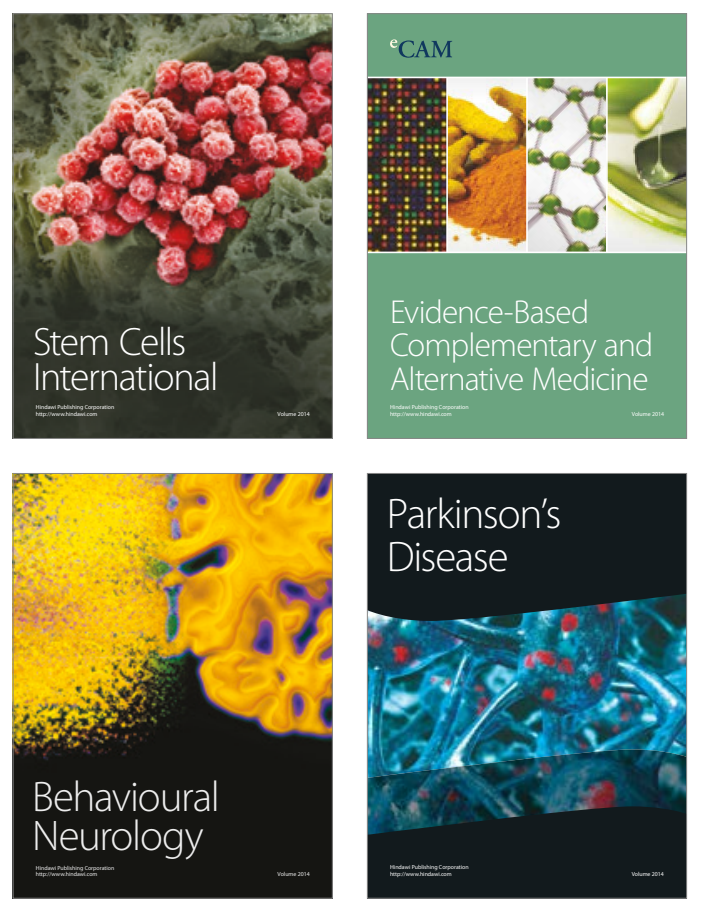
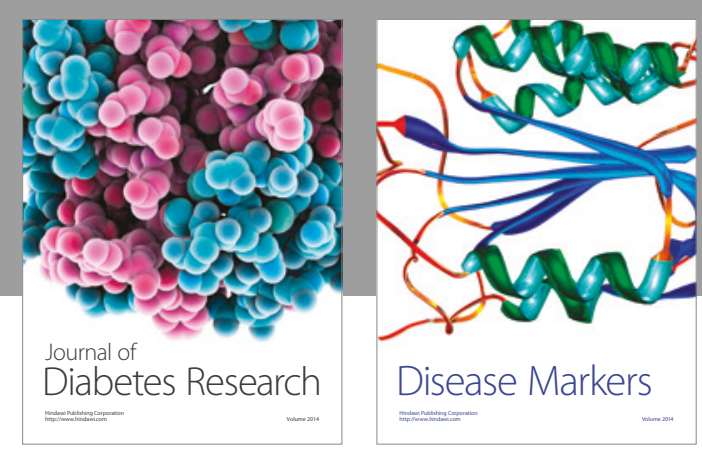

Disease Markers
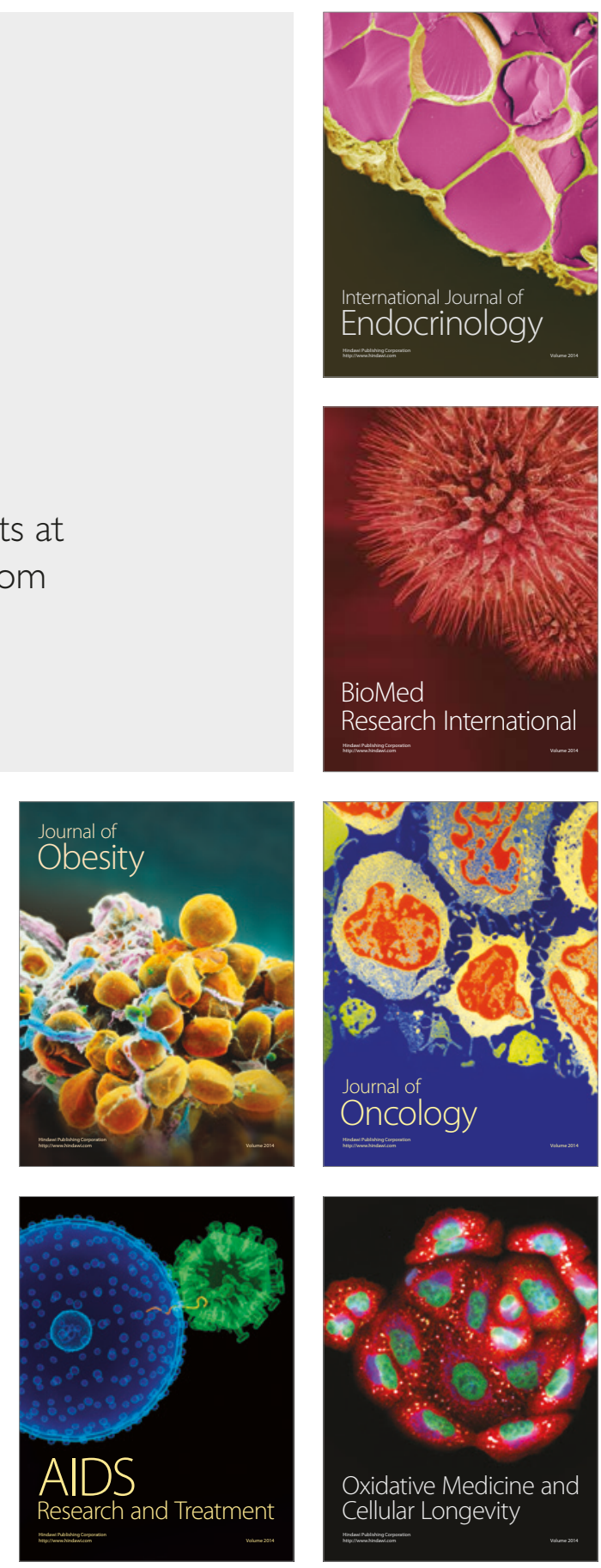